\title{
Synthesis and topotactic manipulation of layered oxysulfide $\mathrm{CaSrMnO}_{2} \mathrm{Cu}_{4-\delta} \mathrm{S}_{3}$
}

\author{
V. Falkowski, S.J. Clarke \\ University of Oxford, Inorganic Chemistry Laboratory, South Parks Rd, Oxford, OX1 3QR, UK \\ viktoria.falkowski@chem.ox.ac.uk
}

The utilization of transition-metal based layered compounds is already established in industrial applications. Considering a combination with mixed-anion systems creates an extended pool of materials that can be screened for superior functionality. The option for postsynthetic alterations to the system offers further possibilities to control properties and gives access to kinetically stable products.

Previous works explored the possibility to influence magnetism and reversibly insert lithium in the oxysulfides $\operatorname{Sr}_{2} \mathrm{MnO}_{2} \mathrm{Cu}_{2 m-\delta} \mathrm{S}_{m+1}(\delta \approx$ $0.5) .{ }^{[1-3]}$ While trying to minimize the weight of these materials the compound $\mathrm{Ca}_{x} \mathrm{Sr}_{2-x} \mathrm{MnO}_{2} \mathrm{Cu}_{4-\delta} \mathrm{S}_{3}(x=1 ; \delta \approx 0.5)$ was obtained by ceramic synthesis. The compound consists of antifluorite-type copper sulfide double layers exhibiting a copper deficiency and square planar $\mathrm{MnO}_{2}$ sheets separated by the alkaline-earth cations. Magnetic susceptibility measurements show high-temperature Curie-Weiss behavior and a positive Weiss constant of $9(2) \mathrm{K}$ suggests that the net exchange interactions are predominantly ferromagnetic. The effective magnetic moment of $\mu_{\mathrm{eff}}=5.63(2) \mu_{\mathrm{B}}$ indicates the oxidation of manganese to a $(2+\delta)^{+}$state. Oxidative copper deintercalation provides control over the oxidation state of $\mathrm{Mn}$, while replacing $\mathrm{Cu}^{+}$by $\mathrm{Li}^{+}$under reductive ion exchange conditions (see Fig. 1) also makes the material interesting for battery applications.
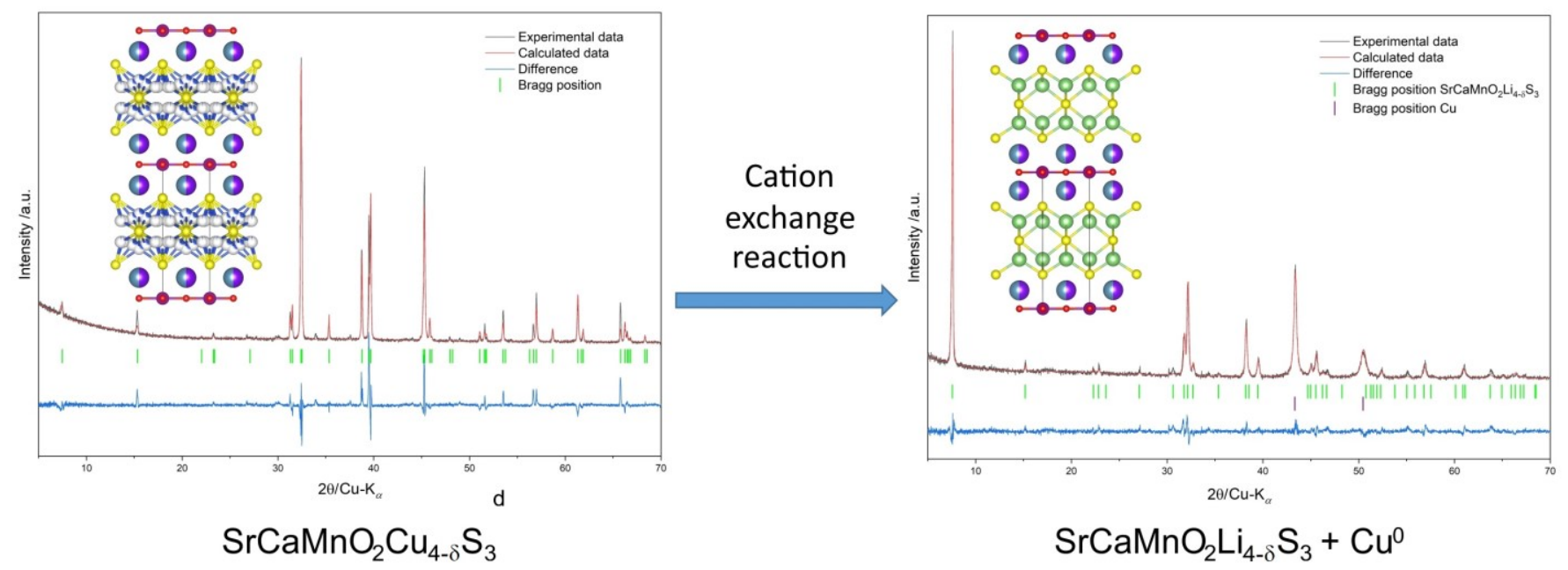

Figure 1: The compound $\mathrm{SrCaMnO}_{2} \mathrm{Cu}_{4-\delta} \mathrm{S}_{3}$ can be topochemically modified by reductive cation exchange to form $\mathrm{SrCaMnO}_{2} \mathrm{Li}_{4-\delta} \mathrm{S}_{3}$.

[1] Blandy, J. N., Abakumov, A. M., Christensen, K. E., Hadermann, J., Adamson, P., Cassidy, S. J., Ramos, S., Free, D. G., Cohen, H., Woodruff, D. N., Thompson, A. L. \& Clarke, S. J. (2015) APL Materials, 3, 041520.

[2] Indris, S., Cabana, J., Rutt, O. J., Clarke, S. J. \& Grey, C. P. (2006) J. Am. Chem. Soc., 128, 13354.

[3] Dey, S., Zeng, D., Adamson, P., Cabana, J., Indris, S., Lu, J., Clarke, S. J. \& Grey, C. P. (2021) Chem. Mater., $33,3989$.

Keywords: Transition metals; Oxychalcogenides; Layered structures 